Acta Poetica 29-1

PRIMAVERA

2008

\title{
Odiseo y el divino porquero: un entretenimiento retórico de Homero (Odisea, XIV)
}

\author{
Pedro C. Tapia Zúñiga
}

Este artículo recrea un diálogo que se da entre Eumeo y el mendigo Odiseo, e intenta mostrar que dicho diálogo es retórico, no sólo por su materia prima, las palabras, sino por manejar ciertos principios artísticos de la retórica, como se entendía en los tiempos clásicos de Grecia: "el arte de conducir a las almas mediante palabras". Eumeo tiene el serio temor de que su amo Odiseo ha muerto y no volverá; el mendigo quiere guiar al porquero a la convicción de que Odiseo está vivo y pronto va a regresar: el estilo de Homero fluye sin que se note la corriente de la buena retórica.

This article recreates a dialogue that takes place between Eumeus and the beggar Odysseus, and the intent is to show that the dialogue is rhetorical, not only because of the words, its prime matter, but by managing certain artistic principles of rhetoric, as understood in the classical period in Greece: "the art of leading souls with words". Eumeus has the quite serious fear that his master Odysseus has died and will not return; the beggar wants to lead the swineherd to the conviction that Odysseus is alive and will soon return: Homer's style flows without his use of good rhetoric being noticeable.

Palabras clave: Homero, Odiseo, Eumeo, retórica, diálogo 

Acta Poetica 29-1

PRIMAVERA

2008

Pedro C. Tapia Zúñiga

\section{Odiseo y el divino porquero: un entretenimiento retórico de Homero (Odisea, XIV)}

Actualmente, como si la falta de materia y de inspiración se hubiera refugiado en la retórica, ésta se ha vuelto una especie de costal en donde caben todas las cosas y, por supuesto, todas las personas: hoy todos hablan de todo en nombre de la retórica; naturalmente, incluso es posible hablar y escribir de ella con un estilo francamente incorrecto. Así, no tengo que dar mayores justificaciones para traerla a colación al recordar el diálogo que se da entre Eumeo (el porquero de Odiseo) y el muy astuto Odiseo que, a la altura del canto XIV de la Odisea, sólo es un anciano miserablemente vestido, feo y hambriento.

Al hablar de diálogo, o de diálogos, automáticamente recordamos a Platón, y estamos en lo justo. Aunque la naturaleza de las cosas nos enseña que el dialogar es lo más simple y antiguo que existe desde que el ser humano está dotado de lenguaje, no hay duda de que la escuela socrática fue su catapulta en la historia de la literatura: Jenofonte, Esquines de Esfeto, Euclides de Megara, Fedón de Elis, Antístenes e incluso Aristóteles dan prueba de ello; sin embargo, fue Platón quien cultivó el diálogo constantemente, y lo consagró como algo grandioso: Nietzsche decía que, cuando la tragedia dejó oír sus últimos acordes, la Musa griega se refugió en los diálogos de Platón. 
Al respecto, hoy parece haber acuerdo en que, más que con la tragedia, estos diálogos se relacionan con la comedia. Nada de esto quiere decir que no haya diálogos anteriores, y muy buenos, pero parece justo aceptar que fueron los discípulos de Sócrates quienes los llevaron a la altura de género literario, quizá imitando por escrito la forma oral en que el maestro dialogaba con sus contemporáneos.

A partir de la traducción que Schleiermacher publicó en 1804 de los diálogos de Platón, se han hecho fervientes estudios y teorías acerca del surgimiento y naturaleza del diálogo. Según nos enseña el profesor Görgemanns, los estudios muestran que el diálogo puede explicarse y entenderse desde varias perspectivas: se ha dicho que su origen se debe a motivos didácticos; que no tiene objetivos teórico-filosóficos, sino que sólo es la muestra de un modo concreto de filosofar; que es, como ya se apuntaba, una herencia socrática; que es un elemento presente en la literatura que se escribía en prosa (Heródoto y Tucídides, en sus respectivas Historias, tienen diálogos sorprendentes); que es una forma de poesía, etcétera. Por cierto, fue Aristóteles quien catalogó los diálogos "socráticos" en el ámbito de la poesía (cf. Görgemanns, pp. 56 y ss.).

Al principio de sus apuntes de Poética (1447a-b), Aristóteles parece decir, según entiendo, que entre los géneros ( $\left.\varepsilon \imath^{\prime} \delta \eta\right)$ poéticos consagrados están la epopeya, la tragedia, la comedia y el ditirambo (en su imitación, estos géneros mezclan las palabras con el son de algún instumento musical, como la flauta y la cítara), y dice que, sin ningún otro medio que no sean las puras palabras, hay otros géneros poéticos que no tienen nombre, como sería el caso de los mimos de Sofrón y de Jenarco, y

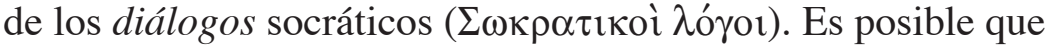
Platón, vivo, se hubiera vuelto a morir al saber que sus diálogos eran catalogados como poesía, después de que él mismo tanto quiso desterrar la poesía de su república ideal (cf. República, p. 396). Ya se han hecho ensayos para resolver esta di- 
cotomía platónica; lo cierto es que, cuando nos comunicamos con palabras, todo es retórica, en su estricto sentido etimológico de "hablar", y que, quizá por lo mismo, nadie niega hoy los nexos de la retórica con la poesía, entendida ésta como una "inefable" forma de hablar.

En los primeros 445 versos del canto XIV de la Odisea hay un diálogo que el mismo Homero refiere; se trata, pues, de un diálogo que debe catalogarse como "diegemático", en oposición al diálogo "dramático", donde, igual que en cualquier drama, los personajes hablan directamente, de tú a tú, como en muchos diálogos de Platón; en los diálogos diegemáticos (de

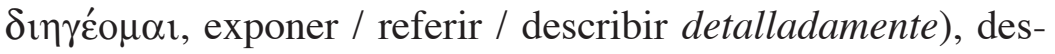
pués de crear el marco de la escena, el autor va introduciendo los parlamentos de los personajes mediante ciertas fórmulas, por ejemplo: "dijo", "dije yo", "dijo él”, etcétera; al respecto, podemos recordar el principio del Lisis de Platón, donde Sócrates cuenta (detalladamente):

Yo caminaba, de la Academia directamente hacia el Liceo, el camino que está fuera de la muralla, precisamente bajo la muralla. Cuando llegué a la puertecita donde está la fuente de Pánope, allí me encontré a Hipótales, el hijo de Jerónimo, y a Ctesipo, el peaneo, y a otros jóvenes que estaban reunidos con ellos. E Hipótales, viéndome pasar, dijo:

- Hey, Sócrates, ¿hacia dónde caminas, y de dónde?

- De la Academia — dije yo-, camino directamente hacia el Liceo.

- ¡Anda - dijo él-, camina directamente hacia nosotros! ¿No vienes? Ciertamente vale la pena.

En la Odisea, después de que Homero crea el marco de la escena, va introduciendo los parlamentos de los dialogantes mediante algunas breves palabras, o fórmulas, por ejemplo: "Le respondió entonces el porquero, príncipe de hombres", o bien "(y Odiseo) esto decía y lo nombraba”, o bien "y (Eumeo) le 
dijo apremiando", etcétera. Se trata pues, sin duda, de un diálogo que Homero introduce en su poema; en estas líneas quisiera mostrar que dicho diálogo (poético) es retórico, no sólo por su materia prima, las palabras, sino por manejar buenos principios artísticos de la retórica, como se entendía en los tiempos

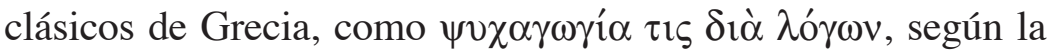
describía Sócrates en el Fedro de Platón (261a 7-8), como “el arte de conducir a las almas mediante palabras". Eumeo tiene el serio temor de que su amo Odiseo ha muerto y no volverá; el mendigo quiere guiar al porquero a la convicción de que Odiseo está vivo y pronto va a regresar. Vayamos al diálogo.

Se trata de un diálogo poético, no sólo por su origen homérico, es decir, no porque es parte de un poema, sino porque tiene algo o mucho de lo que se le pide a un modo poético de hablar, $\mathrm{y}$, desde mi punto de vista, de un diálogo muy natural, es decir, muy semejante a la realidad y, sobre todo, muy tranquilo: Homero nunca tiene prisa, si no tiene prisa. Por lo mismo, por la naturalidad de la plática entre Eumeo y Odiseo, nadie nota su estilo, un estilo que fluye sin que se note la corriente de la buena retórica, difícil de comentar y, sobre todo, imposible de imitar, al contrario de los -ismos y extravagancias.

Ya que extrapolamos este diálogo de su contexto dentro de la Odisea, quizá es necesario presentar a los dialogantes. Todos conocemos a Odiseo; sin embargo, valga recordar de qué Odiseo se trata a la altura de este diálogo: se trata de un miserable vagabundo. Odiseo, el héroe que vuelve a su patria después de la destrucción de Troya, entra en escena en el canto V. Ahí, tras una sesión de los dioses bajo la presidencia de Zeus, se acuerda su retorno. De momento, acosado por Posidón, Odiseo se encuentra en la isla de Ogigia, entretenido por la ninfa Calipso. Zeus da la siguiente orden a uno de sus hijos queridos (vv. 29-38): 
Hermes, ya que eres tú el mensajero también otras veces, dirás el acuerdo infalible a la ninfa de rizos hermosos, la vuelta de Odiseo de ánimo firme: que él ha de tornar sin compañía de dioses ni de hombres mortales, mas en una balsa de múltiples trabas, sufriendo miserias, él puede llegar el vigésimo día a la fértil Esqueria, el país de los feacios, que son parentela de dioses; ellos lo honrarán mucho, de corazón, como a una deidad, y lo escoltarán en una nave a la tierra patria querida, tras darle abundantemente bronce, oro y ropajes.

Aunque no de buen grado, Calipso acató el acuerdo, y Odiseo, a los veinte días, sufriendo miserias, llegó a Esqueria, el país de los feacios. Allí, en la playa, lo rescató Nausícaa, la hija del rey Alcínoo, y lo llevó a la ciudad (canto VI). Ya en la ciudad, Atenea, "semejante a una joven muchacha que un cántaro lleva" (canto VII, v. 21), le mostró el Palacio, y Odiseo se introdujo cuando Alcínoo y los otros príncipes de los feacios cenaban. Esa misma noche, a pregunta expresa de Arete, la esposa del rey, él cuenta su viaje desde Ogigia hasta el país de los feacios. El canto VIII suele llamarse "Odiseo entre los feacios". Los cantos IX-XII hablan de lo que Odiseo les contó al día siguiente; mejor dicho, la noche del siguiente día, a instancias de Alcínoo, en los versos 572 y siguientes del canto VIII:

¡Anda! Dime estas cosas, y cuenta verídicamente cómo has andado errabundo y a cuáles países de humanos has ido; háblame de éstos, de sus bien habitadas ciudades, de cuantos son acerbos, salvajes e injustos, y de hospitalarios, que tienen un alma que teme a los dioses. Di por qué lloras y gimes adentro de tu alma, al escuchar la suerte de Ilión y de los dánaos argivos.

Tras presentarse, Odiseo les narra el cuitoso regreso que Zeus le dispuso al volver desde Troya, comenzando con los cicones; luego, los lotófagos, el cruel Cíclope; Eolo y los vien- 
tos, los lestrigones, la simpática Circe; su viaje a la casa del Hades y, allí, la entrevista con su madre, con Tiresias, con heroínas y con héroes del pasado lejano y del no tan lejano; su vuelta a la isla de Circe y su partida: las encantadoras Sirenas, Escila, Caribdis, y su fatal encuentro con las vacas del Sol, en la isla de Trinacria. El canto XIII comienza con los siguientes versos:

Así dijo y todos, quietamente, en silencio quedaron, en la sala umbrosa estaban absortos de encanto.

Todos se fueron a dormir, y al otro día, tras otro banquete, embarcan a Odiseo y lo llevan a su patria. Los feacios prácticamente lo tiran en alguna playa de Ítaca junto con todos los regalos que llevaba - Odiseo debió de estar muy cansado, tras narrar en una sola noche todo lo que le pasó desde Troya hasta su llegada a la isla de Ogigia, donde lo rescató la ninfa Calipso-. Homero nos cuenta el despertar de Odiseo, todo azorado y sin saber en dónde se encontraba; su plática con Atenea; la forma en que ellos dos traman el regreso a casa, y cómo Atenea, para que él llegue de incógnito, lo disfraza magistralmente como un viejo, feo, arrugado y vestido miserablemente, de modo que nadie lo reconociera, ni su propia esposa.

Por su parte, Eumeo, quizá por razones épicas, es el "divino" porquero, y es "príncipe de hombres". Los estudiosos han intentado explicar esta adjetivación recurriendo a las famosas cláusulas homéricas, pero Homero parece refutar explícitamente estas conjeturas cuando cuenta la vida de este personaje: su padre "reinaba" en Siria, en dos ciudades de dicha isla: era un rey. El mismo Homero da estos datos cuando hace que Eumeo, a petición del mendigo, cuente algo de su pasado (canto XV, 403-414):

Hay una isla, se llama Siria - quizá la has oído-, por arriba de Ortigia, donde están los retornos del sol; 
no es asaz tan extensa, mas es buena, de veras, rica en bueyes y ovejas, feraz en vino y fértil en trigo. El hambre jamás llega al pueblo, ninguna otra desgracia espantosa se cierne sobre los infelices mortales; y cuando en la ciudad envejece la estirpe de humanos, con Artemis llegando Apolo el del arco de plata, les da muerte, acercándose a ellos con suaves saetas. Ahí hay dos ciudades, y todo entre ellas en dos se divide; en éstas, en ambas, mi padre reinaba, semejante a los dioses, el orménida Ctesias.

Si el orménida Ctesias era un rey, a su hijo le correspondía el título de Príncipe, casi como a don Felipe de Asturias, o como a Guillermo, el Príncipe de Gales, por dar dos ejemplos, sólo que Eumeo razonaba y hablaba muchísimo mejor que ellos, según lo oímos hablar en el canto de Homero. Por cierto, no debe espantarnos eso de que Apolo les da muerte a los ancianos: de acuerdo con la concepción mitoantropológica de los griegos de Homero, cuando alguien moría por causa de la edad o por otras razones tan naturales como desconocidas, explicaban dicha muerte atribuyéndosela a Artemis, si se trataba de la muerte de una mujer, o a Apolo, si se trataba de un hombre (cf. Ameis, III, 280).

Por otra parte, no sabemos qué educación recibió Eumeo; sólo oímos que, cuando era un niño, tan astuto que ya corría siempre siguiendo a su nodriza, fue raptado de su casa y entregado a unos piratas fenicios, y que, tras siete días de navegación, fue vendido en Ítaca a Laertes, el padre de Odiseo (cf. $\mathrm{XV}, 450$ y ss.). Laertes, según parece, se lo entregó a su mujer, Anticlea, la madre de Odiseo, la cual, según dice el mismo porquero, lo crió junto con Ctímena, "la más joven de los hijos que ella parió", y tan sólo algo menos que a ella lo amaba (cf. ib., 363 y ss.). Es posible que Eumeo haya recibido, junto con el cariño, una buena educación técnica, la de sus tiempos; lo cierto es que, según lo presenta Homero, tenía un poco común sentido común, y no le faltaban palabras, ni tenía pelos en la lengua. 
Homero labra el marco de la escena en los cincuenta primeros versos del canto: Odiseo llega al lugar en donde ahora, en Ítaca, después de veinte años, su porquerizo Eumeo tiene y cuida sus puercos. Se trata de un establo bien trabajado por este hombre; ahí hay un corral hecho con piedras y rodeado de estacas densamente frecuentes, encornizadas con espinas. Adentro había construido doce pocilgas para las puercas de cría; los puercos, que eran muchos menos (trescientos sesenta), dormían afuera. Unos perros feroces lo ayudan en la tarea de vigilar el establo. Este hombre reparaba sus sandalias cuando el mendigo se acercó al lugar, y poco faltó para que dichas fieras lo despedazaran en un santiamén: le valió que Eumeo, tras notar su furia, tiró las sandalias, les gritó fuerte y los ahuyentó a pedradas; por supuesto, también ayudó el prudente Odiseo que, ante el inminente ataque, "con astucia sentose y soltó su bastón de la mano" (v. 31). Tras el incidente, Eumeo se queja ante el extranjero que, de haber sido destrozado, le habría arruinado del todo la existencia: Eumeo sufría horrores por la ausencia de su amo que, si vive, sufre penurias y hambre, mientras él, Eumeo, cuida puercos para que traguen los pretendientes de Penélope. En seguida, lo invita a pasar a su choza en donde con solicitud le prepara un lugar para que se siente.

Naturalmente, dice Homero, Odiseo se alegró de que el porquero lo acogiera en tal forma: y esto decía y lo nombraba (vv. 53-54):

Zeus te conceda, extranjero, y los otros dioses perpetuos, lo que tú más deseas, por haberme acogido benévolo.

Se trata de unas palabras de gratitud, objetivamente sinceras. Cuesta pensar que alguien las malinterprete, y la interpretación que el porquero hace de ellas sólo se explica si uno se pone en su lugar, porque, como se ha repetido hasta la sacie- 
dad, quidquid recipitur, ad modum recipientis recipitur. Eumeo sólo entendió lo que podía entender; él era un hombre correcto, temeroso de los dioses y lleno de sentido común; sin embargo, conocía esa especie de fórmula para decir "gracias", una que, si bien puede ser muy sincera, puede conllevar la esperanza de obtener algo más, de inmediato o en otra ocasión. Además, dados los usos homéricos, la expresión parece regia (cf. XVIII, 112-113) y, como tal, le queda muy bien al Odiseo que nosotros conocemos, pero Eumeo tiene enfrente a un pordiosero cuya gratitud está muy condicionada por su necesidad. Como se nos dirá más adelante, Eumeo ya tenía otras experiencias semejantes; ya había sido timado por alguno o algunos otros mendigos de esta ralea, aduladores que, con tal de asegurarse comida y vestido, mentían inventando y diciendo lo que saben que quiere oír quien los recibe en su casa. El poeta mismo, conocedor de estos y otros detalles, al darle la palabra a Eumeo en el verso 55, se dirige a él como sonriendo: y respondiendo, porquerizo Eumeo, tú le dijiste (vv. 56-59):

Extranjero, no me es dado, ni si llega más pobre que tú, despreciar a un huésped; de Zeus en efecto son todos los mendigos y huéspedes. Un regalo, aun pequeño, afectuoso hay de nuestra parte...

Estas palabras eran de esperarse, muy naturales; con ellas, Eumeo se encargó religiosamente de poner al mendigo en su lugar. Eumeo no recibe al extranjero por sus atuendos y encantos personales: difícilmente puede uno imaginarse a alguien en peores fachas que las de Odiseo. No obstante, aun si alguien llegara en peores condiciones, sería bien recibido, porque Zeus es el protector de los mendigos y de los extranjeros. Eumeo, pues, parece decirle que se ahorre sus palabras, ellas no dicen nada nuevo, y no lo hospedará bien por ellas, sino porque es temeroso de Zeus hospitalario. 
Odiseo que, como sabemos, por ahora sólo es un miserable, aunque él mismo, como es natural, se sienta Odiseo, ya se pensaba en su tierra y, después de veinte años, casi en su casa; él se equivocó al expresar su gratitud de ese modo, lo traicionó la emoción; ése es su error, un error típico de las discusiones erísticas: olvidarse de la razón y hablar con los sentimientos. Odiseo, merced a su experiencia de diez años de vagabundeo, sabía muy bien y debía de haber recordado cómo hablan los mendigos y cuán arrastradas suenan las palabras de un desgraciado que pide clemencia, u hospedaje, sobre todo comida y algún trapo para vestirse. Así se ha iniciado el díalogo, con muy malos augurios para nuestro mendigo. En seguida, una vez aclarado que este mendigo satisfará sus necesidades, comida y hospedaje, el porquero habla de sus preocupaciones: su dolor de cabeza son los pretendientes, y su afrenta, la ausencia de su amo, probablemente su muerte.

Continuando las palabras del porquero, Homero introduce el tema del diálogo, haciendo que aquél explique por qué no le puede ofrecer gran cosa al mendigo. El porquero se explica diciendo que es condición de los siervos tener miedo, cuando tienen el mando unos amos nuevos, es decir, los pretendientes, que actualmente señorean en el palacio, y dice que ellos señorean, porque los dioses impidieron el retorno de su amo, quien, gentil como era, lo habría querido y le habría dado bienes, cuanto un bondadoso señor le concede a un siervo que trabaja por él. En seguida añade que eso parece irreal, porque aquél murió en su viaje a Troya, para desagraviar al atrida Agamenón. Dicho esto, se fue a las pocilgas, tomó dos puerquitos, los sacrificó y los hizo trozos. Tras asar la carne, aún caliente la puso al lado de Odiseo, en los mismos espetos, y le sirvió su vino, y se sentó enfrente de él: y le dijo apremiando (vv. 80-84):

Come ahora, extranjero, esto que tienen los siervos, lechonada; los pretendientes se comen los puercos cebones, 
sin pensar en su mente en piedad ni en castigo divino.

Sin duda, los felices dioses no aman las crueles acciones, sino que honran lo justo y los hechos sensatos del hombre.

Amén de si se nos antojó esa lechonada, el final, sentencioso, da pie a la plática de Eumeo sobre los atropellos que los pretendientes cometen en el palacio: soberbios y sin ningún miramiento, devoran los bienes, como si supieran con toda certeza que el rey ya había muerto. Afortunadamente, su amo era muy rico, y el porquero hace un recuento de sus realmente inmensas posesiones, en Ítaca y en el continente; en síntesis, ni veinte varones juntos tienen tantas riquezas como su amo. De todas partes, diariamente, los pretendientes recibían lo mejor; Eumeo, por ejemplo, cuidaba los puercos y, eligiendo bien, todos los días les hacía llegar el mejor de ellos. Mientras tanto, el mendigo comía y bebía en silencio, según Homero, tramando la ruina de los pretendientes; en realidad - creo-, pensando qué y cómo contestaría, para ganarse al porquero, para llevarlo a la convicción de que Odiseo está vivo. Sin más preámbulo, dice Homero que el vagabundo, alzando la voz, le dirigió estas palabras aladas (vv. 115-120):

Oh amigo, ¿quién, pues, te compró con sus bienes, así de tan rico y potente cual tú me lo cuentas?

Dices que por el desagravio de Agamenón, aquél pereció.

Háblame de él, por si acaso conozco a quien era tal hombre.

Ciertamente Zeus sabe esto $-\mathrm{y}$ los otros dioses perpetuos - ,

que daría noticias de él, si lo he visto, pues mucho he vagado.

El mendigo empieza con una pregunta y termina con una propuesta. ¿Qué quería saber, qué le propone a Eumeo? Según Platón, el enciclopédico conocimiento que Gorgias de Leontini tenía de la retórica incluía también el saber qué preguntas requerían una respuesta larga, y cuáles, una breve (cf. Gorgias, 449b 9-c 8); dicho saber también se le atribuía al patriar- 
ca de la retórica, a Protágoras que, según el diálogo que lleva su nombre (cf. 334e 4-335a 1), no sólo tenía dicha habilidad, sino la capacidad de enseñarla a otros: qué se requiere para el

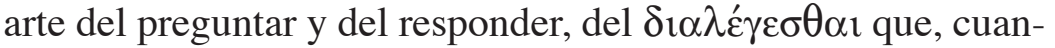
do es tormentoso, da pie a lo que se conoce como erística. Vale apuntar, volviendo al tema, que Homero no se queda atrás: su macrología le permite llenar cuatro cantos de la Odisea, narrando las aventuras de su héroe desde Troya hasta el país de los feacios (cf. cantos IX-XII), y su braquilogía logra resumir la Ilíada en un verso de la Odisea, por citar un ejemplo: en el canto X, Odiseo comienza contando su llegada a Eolia, la isla de Eolo; y, hablando de éste, les dice a sus oyentes, los feacios, en los versos 14-16:

Me hospedó todo un mes y me hacía preguntas de todo, de Ilión, de las naves argivas, del retorno de los aqueos; y yo le conté cada cosa conforme a lo justo.

Valga agregar que tanto la braquilogía como la macrología de Odiseo se deben a la habilidad de Homero, igual que están en las manos de Platón los parlamentos, breves o largos, de sus personajes: unos y otros hablan, respectivamente, cuanto quiere Homero, y sólo dicen eso que Platón les permite. Mientras al porquero se le concedieron 58 versos, Odiseo interviene con 6 , cuyo contenido se reduce, como ya se apuntaba, a una pregunta y a una propuesta. Sin duda, su pregunta podía ser más breve; por ejemplo: "Dime el nombre de tu amo". Sin embargo, en tal caso, no le habría hecho saber al porquero que, aunque comía y bebía, lo había escuchado con mucha atención, y que ya sabe que su amo era una maravilla ( $\tau$ oîo $)$ ): muy rico, muy poderoso y participante en la guerra de Troya. Esto debió de haber impresionado bien a Eumeo, ya sorprendido de que el fulano ese lo interpelara diciendo "Oh amigo". Cabe hablar de un acierto de Odiseo; desgraciadamente, en su propuesta 
vuelve a herir la susceptibilidad del porquero que, olvidando la pregunta, cuya respuesta hubiera podido ser monoléxica, rebate la propuesta de "yo podría dar noticias de él, si lo he visto, pues mucho he vagado". Y se dice que, entonces, le respondió el porquero, príncipe de hombres (vv. 122-125):

Oh anciano, ningún hombre, llegando errabundo con una noticia de aquél, convencería a su esposa y a su hijo querido, sino que es de otro modo, los vagabundos, necesitados de ayuda, mienten, y no quieren decir la verdad.

Con mucha sensibilidad, sin querer ofender los pobres harapos del mendigo, Eumeo habla en abstracto, argumentando que ya han llegado otros con el mismo cuento, y lo único que hacen es decir patrañas que sólo hacen llorar a su dueña. Quizá ante el recuerdo lloroso de esta mujer que lo quiso y lo quiere como a un hijo, Eumeo quiere cortar por lo sano, no quiere que otro tipo más vaya al palacio a lastimar el corazón de Penélope. Y, por si su argumentación no hubiera sido clara, agrega directamente, en concreto (vv. 131-132):

Tú mismo, anciano, al punto podrías inventar un discurso, si alguien te diera vestidos, el manto y la túnica.

Casi sobra cualquier comentario, pero valga apuntar que Eumeo, quizá por prudencia, ya no quiso repetir el aserto con que terminó al hablar en abstracto; quizá comenzó a notar que, aunque harapiento, el extranjero tenía lo suyo y podía deducir lo que pensaba: que él, igual que otros mendigos, necesitando ayuda, mentiría y no se atrevería a decir la verdad. En lugar de eso, él mismo continúa su discurso pronunciando esa verdad que no quieren decir los otros y él no acaba de creer: su amo ha muerto. Las aves y los perros ya deben haberle desgarrado la piel, o los peces lo devoraron y las arenas cubren sus huesos. Los versos que sigue diciendo el porquero, el modo como 
revela el nombre de su amo - como decía Dionisio de Halicarnaso (Comp. VI, 3, 7) al hablar de otro pasaje de la Odisea-, vale más citarlos que comentarlos (vv. 137-147):

Así se murió por allá, y a sus amigos futuras tristezas ha causado, a todos, a mí sobre todo, pues ya a ningún otro señor tendré así de afectuoso, vaya yo adonde vaya, ni siquiera si vuelvo otra vez de mi padre y mi madre a la casa en donde antes nací y aquéllos me criaron. Ni por ellos, ya no lloro tanto, aunque mucho deseo con mis ojos mirarlos, estando en mi tierra paterna; mas del ausente Odiseo la nostalgia me toma. Cierto, oh extranjero, yo a él, aun ausente, nombrarlo me apena; tanto me amaba y en su alma de mí se ocupaba; en vez de eso, lo llamo 'querido', aunque lejos se encuentre.

Nuestro mendigo no debió de quedar menos que muy perplejo ante estas palabras, sin saber si llorar ante tanta ternura de Eumeo hacia Odiseo, o rabiar por su propia incapacidad de congraciarse con él, o poner el grito en el cielo ante tan obstinada convicción sobre la muerte del amo. De hecho, su respuesta parece una mezcla de todo. Homero lo sabía, y, quizá por lo mismo, introduce a Odiseo calificándolo, como lo hace muy a menudo, pero aquí con una puntería de apache, el paciente. Creo que vale la pena leer toda su respuesta: le contestó entonces el paciente, divino Odiseo (vv. 149-164):

Oh amigo, pues niegas del todo, y ya ni supones que aquél tornará, y siempre tienes un ánimo incrédulo; pero no diré así, simplemente, mas con un juramento, que Odiseo volverá. Y por mi buena noticia haya premio después, cuando, tornando, aquél venga a su casa -el vestirme con túnica y manto, unos bellos vestidos-, antes, aunque muy indigente estoy, yo no aceptaría. Pues para mí, odioso igual que las puertas del Hades, aquél es, el que dice patrañas cediendo a su dura pobreza. 
Hoy, de los dioses, Zeus lo sepa primero, y la mesa hospital

y el hogar del noble Odiseo, al cual he llegado:

ciertamente todo esto se te ha de cumplir como digo.

Durante este mismo año, aquí ha de volver Odiseo,

cuando termine esta luna y la nueva comience,

de regreso a su casa, y habrá de punir a quienquiera

que aquí le deshonre a su esposa y a su hijo preclaro.

Son variadas las versiones de los tres primeros versos de la respuesta. Por lo que toca al primero, quienes se interesan en el griego, pueden ver, en la Odisea, I, 321 = XV, 390; III, 103 y 211; en todos estos lugares, غ̇ $\pi \varepsilon i ́$ parece tener el valor de una conjunción causal, pero es una causalidad tan sutil, que hace pensar en que dicha partícula sólo introduce una oración principal (cf. Bornemann, $\S 274$, nota 1); pienso que el "pues" funciona bien en cualquier caso. Es posible que la variedad de versiones se deba a la obscuridad del texto de Homero, y ésta, a la dificultad que hay para expresar bien el asunto, cuando están de por medio las emociones. El mendigo Odiseo está emocionado y, a la luz de lo que le dijo Eumeo, no es del todo justo al decirle lo que le dijo, y, menos, que siempre tiene un ánimo incrédulo: una cosa es que, para disuadirlo de que vaya a hablar con Penélope, le diga que su amo ha muerto, y otra, muy distinta, que esté convencido de ello, y de que ya no crea que volverá; en su parlamento, al revelar el nombre de su amo, sólo habla del "ausente Odiseo", y terminó diciendo: "lo llamo 'querido', aunque lejos se encuentre".

En seguida, el verso 151 comienza con un $\alpha \lambda \lambda \alpha \dot{\alpha}$ (= pero).

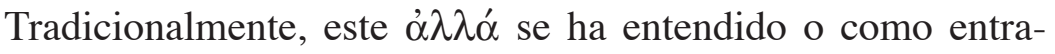
da de una aseveración enfática - lo cual puede ser cierto-, o como la entrada de una oración subordinada a la cual le falta su oración principal — también es posible-. Desde mi punto de vista, el mendigo mismo se dio cuenta, y pronto, de que se sobrepasó afectivamente en los dos primeros versos que, de hecho, enjuician duramente al porquero. Por lo mismo, tras 
caer en la cuenta de que su discurso no va a funcionar, le cambia la perspectiva mediante dicho $\alpha \lambda \lambda \lambda \dot{\alpha}$ : para ganarse la opinión del porquero, ya no hablará así, simplemente, sino con un juramento: los estudiosos de la retórica hablan de la figura

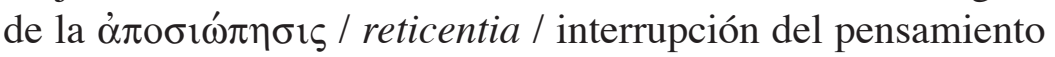
(cf. Lausberg, §§ 411 y 414). En seguida, en el mismo verso, usa otro $\dot{\alpha} \lambda \lambda \alpha$ que no tiene mayor elegancia anafórica con el $\dot{\alpha} \lambda \lambda \alpha^{\prime}$ anterior, sino mucho de nerviosismo: el mendigo tiene algo así como ansias de ganarse al porquero... Ya a punto de jurar, él se da cuenta de que sus palabras serán inútiles, si no le quita a Eumeo sus temores de que él mismo no sea más que uno de tantos charlatanes que no quieren decir la verdad, sino sólo asegurarse un vestido. Quizá es demasiado tarde.

En seguida, el mendigo habla bajo juramento. Antes de oír la respuesta de Eumeo, valga recordar que, como entre nosotros se oye "te juro por mi madre", o "te juro por la virgen de...", o "te juro por dios", etcétera, los griegos de Homero tenían tres tipos de juramento: uno es el gran juramento de los dioses: con él jura Euriclea, la nodriza de Odiseo, que no dirá nada a Penélope acerca del viaje que Telémaco hará en busca de su padre (Odisea, II, 377); este juramento le hace Calipso a Odiseo en V (vv. 184-187):

Sean testigos hoy, la tierra y el cielo anchuroso en la altura, y de la Estigia el agua que fluye hacia abajo (el más grande juramento es éste, y el más terrible entre dioses felices), de que no planeo en tu contra ningún otro daño maligno.

Como si se dijera "te juro por el cielo y por la tierra y por los infiernos". Otro tipo de juramento es el que acaba de hacer el mendigo: por Zeus y por la casa que recibe al jurante (estas palabras se vuelven a oír en XIX, 303); en otro tipo de juramento, el tercero, se jura simplemente por los dioses que poseen el Olimpo, unas palabras que escucharemos más adelante, en el verso 394, también en boca de nuestro mendigo. 
Volviendo al diálogo, el mendigo habló y juró, y nosotros, que sabemos todo lo que está sucediendo, nos ponemos de su parte: él no quiere recompensa (inmediata), sino convencer a Eumeo de que su amo Odiseo volverá. Pero Homero - el que nos está refiriendo el diálogo - no está de acuerdo en que este entretenimiento retórico con que retarda la acción de su Odisea deba terminar con la alienación de un juramento, y se

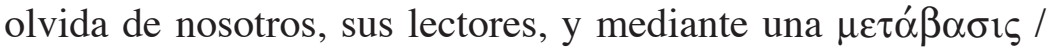
aversio / desviación "de persona” (cf. Lausberg, §§ 442-443) se dirige al porquero, y respondiendo, porquerizo Eumeo, tú le dijiste (vv. 166-173):

Oh anciano, pues ni yo he de pagarte esta buena noticia, ni Odiseo algún día ha de volver a su casa. Tranquilo sigue bebiendo, y mejor otras cosas pensemos, y de ésas no sigas haciendo memoria: cierto, mi alma en el pecho se entristece cuando alguien a mi amo querido menciona. Desde luego, el juramento olvidemos; empero Odiseo ojalá vuelva, cual quiero que vuelva y lo quiere Penélope y Telémaco, símil a un dios, y el anciano Laertes.

Aquí, a primera vista, puede entenderse que Eumeo le dice suavemente al mendigo, que mejor ya no hable, porque únicamente lo pone triste; sin embargo, nadie puede negar que el mendigo había hablado muy en serio, con un juramento, y el principio de la respuesta del porquero, si no es irreverente, por lo menos resulta irónico, quizá acompañado de una ligera sonrisa. Pero el mendigo mismo es el responsable de ello al prologar el juramento con su "de mi buena noticia haya premio / después". Nosotros entendemos las buenas intenciones de ese discurso, pero el porquero no sabe lo que sabemos $\mathrm{y}$, de nuevo, el mendigo se equivoca. Eumeo fue piadoso al escuchar todo el juramento, porque, tras esas palabras del mendigo, sólo debió de hacer algún gesto y decirse para sus adentros: “¡Otro más, otro de los que no pueden hablar sin esperar 
recompensa!" En el primer verso de su respuesta, el porquero vuelve a cortar por lo sano: no habrá recompensa; y a la luz del "tranquilo / sigue bebiendo" ( $\pi \hat{i} v \varepsilon$, imperativo presente), cabe imaginar que le dio una palmadita en el hombro.

Ciertamente Eumeo parece no haber respondido con una argumentación adecuada. En su Retórica (1419b 3), Aristóteles escribe que Gorgias, hablando rectamente (o’ $\left.\theta \hat{\omega} \varsigma \lambda^{\prime} \varepsilon \omega v\right)$, decía que era conveniente destruir la seriedad de los contrarios con la risa, y su risa con la seriedad. Si el mendigo hubiera podido tomar la palabra de inmediato, podría haber dicho casi lo mismo que Sócrates le dijo a Polo, con enfado: “¿Qué es eso, Eumeo? ¿Te ríes? ¿También ése es otro tipo de demostración, reírse cuando uno dice algo, mas no refutar?" A lo cual, Eumeo pudo responder del mismo modo que Polo a Sócrates, en el mismo diálogo: “¿No crees, extranjero, que ya estás refutado, cuando dices tales cosas, unas que no afirmaría ninguno de los hombres? (cf. Gorgias, 473d-e). Desde luego, no estamos ante un pleito verbal, $\alpha \gamma \omega ̀ v ~ \lambda o ́ \gamma \omega v$, erístico (o sofístico), en el sentido estricto del término (cf. Sofista, 225-226a), de esos que Sócrates reprobaba, pero manejaba a la perfección. Sin embargo, como los procesos judiciales y los discursos políticos en la Grecia clásica eran un pleito con palabras para ganarse, respectivamente, a los jueces o la opinión del pueblo, del mismo modo los diálogos —oficialmente los sofísticos; de hecho, también los platónicos - son un "pleito" con palabras, para ganarse la opinión del otro dialogante (cf. Baumhauer, pp. 3238). Nuestro mendigo quiere ganarse al porquero, desea que crea que Odiseo volverá. Y algo le está fallando.

O, según los versos con que Eumeo sigue su respuesta, ¿debemos imaginarlo pensativo y triste y comprensivo? El cruel de Homero no nos da ningún indicio de gestos o ademanes que acompañen a las palabras; tenemos que imaginarlos, y la imaginación no tiene límites. Pareciera que Eumeo, después de medio oír el juramento, quizá ya pensando en lo que iba a 
responder, habló con el alma, y tras decir lo que le interesaba decir, recordó que se había tratado de un juramento y, temeroso de los dioses como era, volvió sobre él y agregó lo que ya leímos: "desde luego, el juramento olvidemos". En su epigrama XXV, Calímaco escribió sabia y quizás irónicamente, que los juramentos de los enamorados no entran en los oídos de los dioses (de lo contrario, todos serían unos perjuros). Sin duda, Eumeo, tras decir "olvidemos el juramento", pudo haber agregado en silencio, "porque los juramentos de los menesterosos no entran en los oídos de los dioses", ya que ellos mienten por hambre, y "otra cosa más perra que el vientre terrible / no existe" (cf. VII, 216-217). En seguida, con el tono o gestos que queramos imaginar, Eumeo refuta los reproches con que el mendigo comenzó su discurso; Eumeo parece repetirse: dije que Odiseo ha muerto, porque no quiero que vayas a fastidiar a Penélope con inventos que hemos oído hasta la saciedad de otros mendigos como tú; en realidad, por lo que a mí toca, ojalá que vuelva Odiseo, como quiere Penélope y Telémaco y el viejo Laertes.

En lo que sigue de su parlamento, Eumeo, consecuente con lo que acaba de sugerir, cambia de tema. Ahora habla de sus preocupaciones acerca de Telémaco, a quien acaba de mencionar, y que se ha ido de Ítaca en busca de noticias de su padre. Sin embargo, pareciera que Eumeo teme que su cambio de tema pueda provocar un volver sobre lo mismo, y, por eso, corta de un tajo su queja sobre el destino de aquel Telémaco (vv. 183-192):

Mas, por cierto, olvidemos a aquél: o será capturado o escapará, y extenderá el Cronión la mano sobre él. ¡Mas, anda, oh anciano! Tus cuitas cuéntame ahora; también dime estas cosas verídicamente, a fin de que sepa. ¿Quién eres tú, de qué gente? ¿Dónde, tu ciudad y tus padres? ¿En qué tipo de nave llegaste, y cómo los nautas te trajeron a Ítaca? ¿Quiénes se precian de ser? 
Pues no, no creo que por tierra hayas llegado hasta aquí.

Y respondiendo, le dijo el muy astuto Odiseo:

Pues bien, esas cosas, muy sincero yo voy a decirte.

Y, tras un preámbulo de seis versos, le inventa una reata de mentiras que se alarga hasta el verso 359 del canto. De aquí, por ahora, sólo nos interesan los 13 versos que van del 321 al 333. Pero estos versos no funcionarían si no sabemos algo de los otros, anteriores y posteriores. De unos y otros, e incluso de los 13 de que luego hablaremos, vale decir que, exceptuando unos cinco, los demás son puro cuento, pero dignos de lectura atenta, y por varias razones: en su Poética (1460a-b), Aristóteles nos confiesa que, más que nadie, Homero enseñó, incluso a otros poetas, cómo hay que decir mentiras como se debe, y que lo absurdo que le encontramos - que no debemos perdonar en los malos poetas - pasa, porque lo encubrió con el deleite de otras cualidades.

En los versos anteriores y posteriores, el currículum del mendigo Odiseo se envuelve en un paño de lágrimas muy bien teñido de cualidades: hábil en cuestiones bélicas, no le gustan las cosas domésticas que educan a hijos preclaros; es un hijo espurio de una querida de su padre, tras cuya muerte sus hermanastros le dieron muy poco; lo abruman grandes miserias; 'participó en la guerra de Troya, donde los aqueos lucharon nueve años y destruyeron la ciudad de Príamo; al regresar, un dios los dispersó' (¡una verdad!). Después, dado a una vida de pirata y aventurero, dice acá y allá patéticamente: "para el pobre de mí, el próvido Zeus decidió la desgracia”; “ojalá hubiera muerto"; "me embarcaron rumbo a Libia, para que allí me vendieran"; "vertiendo mi llanto"; "teniendo dolores en mi alma"; "un acuerdo maligno sobre mí, para que ya del todo cayera en el mal de los males"; "me quitaron mis vestes"; "me eché a tierra, escondiéndome", y al final, los dioses "de un hombre sensato al establo / me acercaron: sin duda, vivir 
todavía es mi destino" (¡la otra verdad!: llegó al establo de Eumeo). Con palabras ( $\left.\delta i \grave{\alpha} \lambda o^{\gamma} \gamma \omega v\right)$, como trabaja la retórica ver-

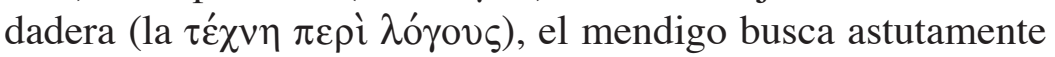
la persuasión $(\pi i ́ \sigma \tau \imath \varsigma)$ del porquero.

Aparentando aceptar el imperativo de Eumeo - "no sigas haciendo esas memorias; anda, mejor cuéntame tus cuitas, dime quién eres"-, el mendigo usa sus palabras para influir afectivamente al que domina la situación (Eumeo), quiere pro-

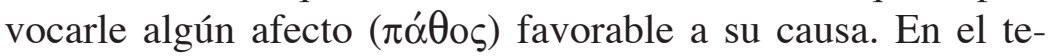
rreno de las pasiones, según enseña Aristóteles, puede hablarse de "conmiseración, de temor, de ira y de otras semejantes" (cf. Poética, 1456a 32 y ss.). Según entiendo, nuestro mendigo hace unas narraciones patéticas, retepensadas por Homero, en busca de la conmiseración del porquero. Y cuando, después de unas historias miserandas, cree tenerlo de su lado, vuelve sobre lo suyo: Odiseo tornará, ya está en camino, ya viene. En su penúltima desgracia, tras una noche brumosa, llegó náufrago al país de los tesprotos, donde lo rescató el hijo del rey Fidón; éste le dio hospedaje, y su cuento sigue en los siguientes términos (vv. 321 al 334):

Allí me enteré de Odiseo; Fidón, en efecto, me dijo que lo hospedó y acogió cuando él iba a su tierra paterna; también me mostró las riquezas que había reunido Odiseo, bronce y oro y fierro, elaborado con arte.

Aun a otro alimentaría hasta su décima generación: ¡En tal cantidad en la sala del rey las joyas se hallaban!

Mas decía que él había ido a Dodona, a escuchar el designio de Zeus, desde la encina del dios, la de fronda elevada: cómo él podría regresar a Ítaca, el fértil país - tras ausencia tan larga-, si de frente o a ocultas. Y además, libando en su casa juró en mi presencia, que una nave había sido botada, y listos estaban los socios que lo iban a escoltar al punto a la tierra patria querida. Mas me despidió antes, pues salió casualmente una nave. 
Las virtudes de este incidente merecerían un comentario aparte. Por lo que toca a nuestro diálogo, valga apuntar que el mendigo se ve tan astuto como desobediente al insertarlo en este preciso lugar de su narración: sabiendo que tenía prohibido tocar el tema, lo inserta como un simple incidente después de contar muchas otras desventuras, cuando cree que con ellas ya se ha ganado el afecto de Eumeo, y que éste había olvidado su prohibición. Además, la narración entra con mucha naturalidad ("allí me enteré de Odiseo"); es breve, como para que no se note mucho la desobediencia, y, tras coronarla con el juramento de otro, sigue como había empezado, con naturalidad magistral, el relato de otra miserable cuita, como para que Eumeo sienta verosímil que lo de Odiseo fue algo tan incidental, como fueron reales sus otras aventuras. La nave que salió casualmente lo debía llevar a su patria, a Duliquio, y los siguientes versos son una síntesis de los 25 con que casi termina su parlamento (vv. 339-343):

Cuando bogaba lejos de tierra la nave que cruza los mares, inmediatamente, el día de mi esclavitud maquinaron.

Me quitaron mis vestes, el manto y la túnica, me echaron en torno otra ropa, fea, y, también, otra túnica rota, la que ante tus ojos tú mismo contemplas.

Esta aventura sigue, y con su astucia paradigmática, el mendigo la termina diciendo que, finalmente, porque su destino era seguir viviendo, los dioses lo guiaron al establo de un hombre "sensato". Eumeo debió de sentirse un poco embarazado ante esta sensatez que le concedió el mendigo, pero ni eso ni los increíblemente tristes relatos que acaba de escuchar lo hacen desistir de su buen juicio: no quiere que este extranjero, como otros, vaya a perturbar el corazón de Penélope. Así puede explicarse su respuesta (vv. 361-471): 
Ah, infeliz extranjero; sin duda, mi corazón conmoviste, al contar con detalle cuanto has padecido y errado.

Mas pienso que no hablaste en lo justo, y no me convences al hablar de Odiseo. ¿Por qué debes tú, cual te encuentras, mentir vanamente? También sé yo mismo muy bien, del retorno de mi amo, que por todos los dioses odiado fue del todo y, por eso, entre los teucros no lo mataron, ni en los brazos amigos, tras haber realizado la guerra. Así, todos los aqueos le habrían erigido una tumba y para su hijo habría conseguido gran fama futura. Mas hoy, las Harpías lo arrebataron sin gloria.

Es malo, dirá Aristóteles, dejarse llevar por las emociones $(\pi \alpha \dot{\theta} \eta)$ : "las pasiones son todo aquello por lo cual los hombres, cambiando, se hacen diferentes en lo relativo a sus juicios; son todo aquello a lo cual sigue pena y placer; por ejemplo la ira, la compasión, el temor y todas las otras emociones que les sean semejantes, y las contrarias a ésas" (Retórica, 1378a 20-23). Odiseo tiene fama de mentiroso (y patético), gracias a Homero, pero este poeta parece no aprobar del todo estos procedimientos. Al respecto, cabe mencionar otra ocasión en que nos muestra a Odiseo en tales lances: así nos lo muestra ante Atenea que, disfrazada de pastor, sólo sonrió ante tantas mentiras, y - quizás en nombre de Homero-, sonriendo, le dijo todas sus verdades, y reprobándolo (XIII, 291-295):

Sagaz sería y mañoso aquel que pudiera vencerte en cualquier tipo de dolos, aun siendo algún dios quien te hallara. Temerario, de variadas astucias, nunca harto de dolos; según veo, no cesaste ni estando en tu tierra, de engaños ni de cuentos arteros que sonte de plano queridos.

No sé si vale decir que Eumeo venció a Odiseo o, simplemente, que no se dejó persuadir. Lo cierto es que Homero no aprueba mentiras ni patetismos retóricos, en el sentido estricto 
del término; igual que con Atenea, a la altura de este diálogo - me parece - , lo que el mendigo se gana es otro reproche: “¿Por qué debes tú, cual te encuentras, / mentir vanamente? También sé yo mismo muy bien, / del retorno de mi amo, que por todos los dioses odiado / fue del todo..." Contra la verdad del mendigo, Eumeo tiene la suya. Y en seguida, las palabras de Eumeo vuelven a su rutina de porquero y a la rutina del palacio, adonde ya casi no va, a no ser que lo llame la muy prudente Penélope, cuando llegan noticias de su amo: ¡Todas han sido puras mentiras! Por cierto, hace tiempo — dice - a él mismo, un etolo lo embaucó con un cuento en esencia muy semejante al que le acaba de contar el mendigo; y por si éste no se hubiera dado por aludido, concluye con un argumento ad hominem que quiere volver al principio del diálogo (vv. 386389):

También tú, deplorable anciano, al guiarte algún dios hasta mí, no quieras serme grato con farsas, ni fascinarme; no habré de honorarte ni habré de hospedarte por ello, mas porque temo a Zeus hospital, y tú mismo me apenas.

Comenzaba a caer la noche de una tarde fría de otoño, Zeus conglomeraba las nubes. Ello y el parlamento de Eumeo dejan claro que éste daba o quería dar por terminada la plática: ya no había más qué decir. Pero el mendigo mendigaba más que al principio su deseo de hacerse creíble y ganarse al porquero; sólo así se entiende que Homero le dé nuevamente la palabra. Respondiendo, le dijo el muy astuto Odiseo (vv. 391-400):

En verdad, en el pecho, muy incrédulo el ánimo tienes; ni siquiera jurando he logrado ganarte, y no te convenzo. ¡Mas anda! Ahora hagamos un pacto, y después sean testigos para ambos los dioses que poseen el Olimpo. Si tu amo regresa a esta morada, vistiéndome vestes, túnica y manto, tú me enviarás 
a que vaya a Duliquio, allí, adonde mi alma quería;

y si tu amo no regresa cual yo te lo digo,

incitando a tus siervos, arrójame de una gran roca,

por que también algún otro mendigo evite engañarte.

Entre las virtudes de la elocución, los estudiosos hablan de la concessio, entendida como una confesión que hace el orador cuando se encuentra en dificultades: confiesa el hecho de que su contrario tiene razón en uno o algunos de sus argumentos (cf. Lausberg, §§ 434-441). Creo que así puede entenderse el inicio de las palabras del mendigo: "ni jurando he logrado

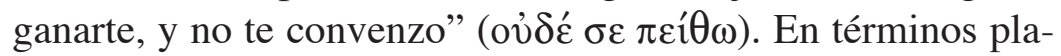
tónico-socráticos, la retórica puede definirse como el "guiar / atraer / seducir al alma mediante palabras"; la retórica es, prag-

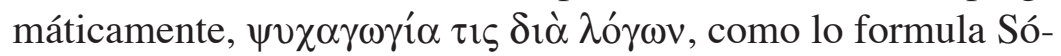

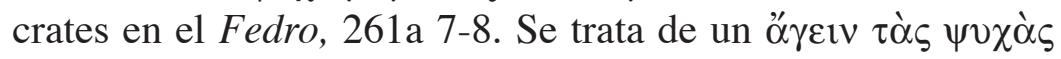
$\delta i \grave{\alpha} \lambda{ }^{\prime} \gamma \omega v$. Sin embargo, Odiseo no habla de un simple ö $\gamma \varepsilon ı v$,

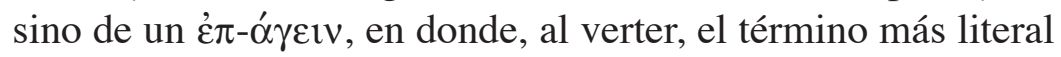
sería "inducir" (induco, infero, inveho; impetum facio; instigo; adduco, affero, como asentaba el profesor E. F. Leopold). Ya Passow nos decía que este verbo, en este verso de la Odisea, está usado metafóricamente; por tanto, dado que el objetivo

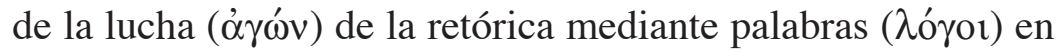
tiempos clásicos era el guiar / atraer / inducir al otro (a los jueces, a la asamblea o simplemente al interlocutor) a que se ponga del lado del que lucha, es creíble que, en nuestro verso, se trata de "ganarse" al otro para la causa propia.

También se dice que, la mayoría de las veces, la confesión abierta es simulada y sólo sirve como medio para ganarse la simpatía del otro, y que, en general, la confesión se resarce en seguida mediante argumentos de mayor peso (cf. Lausberg, $\S \S 436-437)$. A la altura de este diálogo, el mendigo está en serias dificultades, pero sólo simula haber perdido: realmente cree que aún puede ganarse al porquero; por ello, vuelve a la 
carga con otros argumentos: se pone patético y replica vehementemente mediante otro juramento, y se remite - hablando en términos coloquiales - "a los hechos", o, también coloquialmente, se juega el todo por el todo. En síntesis: si tu amo viene, me das lo que te pido, me envías a mi patria, y, si no viene, me mandas matar. Y, cuidado con la adjetivación, respondiendo, le dijo el divino porquero (vv. 402-408):

Anciano, en tal caso, sin duda, buena fama y nobleza
habría para mí entre los hombres al punto y después,
si tras llevarte a mi tienda y darte los dones del huésped,
te asesinara yo, y te quitara la vida querida.
Con limpia conciencia luego oraría ante Zeus el Cronión.
Mas es hora de la cena: ojalá pronto en la casa estuvieran
los míos, por que en la tienda una cena sabrosa aprestáramos.

Al leer estos versos, uno puede imaginar a Eumeo sonriendo con ironía o con benevolencia, o como uno quiera; las razones con que rechaza el pacto son contundentes, sobre todo a la luz de Odisea, XXI, 26-29, en donde Homero tacha a Heracles, "el varón experto en trabajos grandiosos", de cruel, de no tener temor del castigo divino, ni respeto a la mesa que le había puesto enfrente a su huésped Ífito, porque en su propia casa lo asesinó después de darle de comer. Por lo demás, la anotación de que "es hora de la cena" entra con naturalidad: es un hecho que comienza a caer la noche. Pero, ¿por qué referirse a la noche mediante la cena, y no viceversa? Lo ignoro. Es posible - y simplemente posible - que el porquero haga énfasis en su tesis: los mendigos mienten por hambre. Así, este mendigo no tiene que seguir mintiendo ni jurando ni proponiendo pactos: es hora de la cena, ya tiene asegurada la comida. Tras otros dos breves parlamentos, Homero continúa la Odisea de Odiseo, y nosotros dejamos el comentario.

No dudo de que haya dudas en cuanto a esta lectura que se ha hecho, pero pienso que el lector puede enfrentarlas por sí 
mismo. Para terminar esto que intentó ser un comentario retórico, valgan unas líneas sobre el hecho de que, al menos a primera vista, Homero le cierra al mendigo Odiseo todas las entradas y todas sus astucias y todas las salidas: no le concede nada. ¿Por qué? ¿Hay retórica en el diálogo? ¿Cabe hablar de retórica hablando de Homero? Para este último tema, el lector puede leer el trabajo de Bulmaro Reyes Coria (Noua tellus, 14, pp. 9-34). Por mi parte, no quisiera pasar por alto una de mis inquietudes, una que provoca Sócrates cuando afirma que la verdad nunca es refutada (Gorgias, 473b); casi lo mismo, y algo más, afirmaría Aristóteles al decir que, por naturaleza, lo verdadero y lo justo son más fuertes que sus contrarios, lo falso y lo injusto (cf. Retórica, 1355a 20-21). Pero el mendigo Odiseo tenía, sabía toda la verdad. ¿Por qué fue refutado, por qué no tuvo éxito?

Aquí se me ocurre mencionar algo de lo que Sócrates decía sobre los sofistas, según nos cuenta Platón. En el diálogo que lleva su nombre, Fedro dice haber oído que los sofistas afirman que quien pretende ser orador no necesita aprender qué es verdaderamente lo justo, sino lo que le parece justo a la multitud que es quien ha de juzgar; ni lo que es en verdad bueno o hermoso, sino lo que ha de parecer así, pues el persuadir ( $\tau$ ò $\pi \varepsilon i ́ \theta \varepsilon \imath v)$ no viene de la verdad, sino de esas cosas (Fedro, 259e 7-260a 4), es decir, del crear convicción haciendo que algo parezca (justo, bueno o verdadero).

En aquel diálogo, Sócrates aceptó que la doctrina de los sofistas era digna de cuenta, y más adelante atribuye a Tisias y a

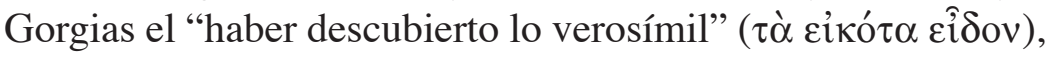
algo que está sobre la verdad y es más estimable (cf. Fedro, 267a 6-7), en el arte de conducir a las almas mediante palabras. Según parece, la retórica de los sofistas se basaba en la convicción de que el oyente no acepta una verdad, si el hablante no logra presentarla como algo verosímil. Al margen de cuál o qué sea la verdad, los sofistas no parecen ni identificarla ni 
contraponerla absolutamente a lo verosímil; más bien postulan que el camino hacia la verdad es lo verosímil, como el camino hacia la realidad es la percepción. Años después, Aristóteles apunta la causa del fracaso de la verdad y de la justicia ante lo falso y lo injusto: si se da el caso de que los juicios - los argumentos en pro de aquéllas - no se hacen como conviene

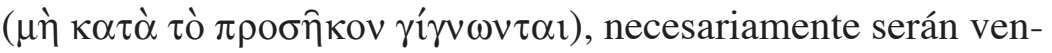
cidas por éstos, es decir, por lo falso y por lo injusto (cf. Retórica, 1355a 21-23). Sobre la práctica no basta saber la verdad para convencer al otro, hay que saber argumentar, como dice Aristóteles; las percepciones y los juicios deben hacerse como conviene, para llegar, respectivamente, a la realidad o a la verdad. ¿Una reformulación de la tesis de los sofistas?

Nuestro diálogo da testimonio de este asunto; no basta saber la verdad - y nosotros podríamos tomar nota de ese incidente-, hay que hablar / escribir de manera que nuestros juicios, nuestros argumentos, sean convenientes, a fin de que resulten convincentes, amén de que, como decía allí mismo Aristóteles, a algunos, ni con la ciencia más exacta resulta fácil persuadirlos.

\section{Epílogo}

¿Qué quería el mendigo en su afán de convencer al porquero de que Odiseo volvería? Desde mi actual punto de vista, sólo quería consolarlo y darle ánimo con la esperanza y la noticia de que su amo ya estaba en camino. El porqué de tanto empeño se explica a la luz de lo que Atenea, planeando el retorno, le ordena y le informa a Odiseo en el canto XIII, 404-406: "antes que nada, ve y busca al porquero, / que es guardián de tus puercos, y afectuoso contigo cual siempre / y quiere bien a tu hijo y a la juiciosa Penélope". Según queda claro, el mendigo no logró nada de lo que quería, y, sin embargo, unos cantos 
más adelante, Homero parece sonreírnos con sonrisa buena, al contarnos qué le dice Eumeo a Penélope acerca de este pordiosero a quien Antínoo en el palacio le acaba de golpear el hombro derecho con un escabel (XVII, 513-527):

¡Si los aqueos, mi reina, guardaran silencio!

Platica tales cosas, que encantaría, sin duda, a tu pecho.

Pues ya tres noches lo tuve y tres días lo mantuve en mi tienda - primero a mí llegó cuando huyó de la nave-, mas aún no ha terminado el recuento de su desventura. Como cuando un hombre observa a un aedo que, instruido por los dioses, les canta a los hombres deseables relatos e incesantemente, cuando él canta, ellos anhelan oírlo, así aquél, sentado en mi sala, me tenía encantado.

Dice que él es, de Odiseo un huésped paterno, que habita en Creta, donde se halla la estirpe de Minos. De allí, hoy llegó hasta aquí de ese modo, sufriendo miserias, yendo de un lado para otro; afirma que oyó que Odiseo cerca, en el rico país de los hombres tesprotos, está vivo; y él trae a su casa muchos tesoros.

\section{Bibliografía}

AmEIs, Karl Friedrich, Homers Odyssee für den Schulgebrauch erklärt von Dr. Karl Friedrich Ameis und Carl Hentze, bearbeitet von Paul Cauer, Leipzig-Berlin, Teubner, 1920-1928.

Aristóteles, Poética, intr. vers. y nts. de Juan David García Bacca, México, unam, Bibliotheca Scriptorum Graecorum et Romanorum Mexicana, 2a. ed., 2000.

-, Retórica, intr. tr. y nts. de Arturo Ramírez Trejo, México, unAm, Bibliotheca Scriptorum Graecorum et Romanorum Mexicana, 2002.

Baumhauer, Otto A., Die sophistische Rhetorik (Eine Theorie sprachlicher Kommunikation), Stuttgart, J. B. Metzlersche Verlagbuchhandlung, 1986. 
Bornemann, Eduard, Griechische Grammatik, unter Mitwirkung von Ernst Risch, Frankfurt am Main, Verlag Moritz Diesterweg, 2a. ed., 1978.

Calímaco, Himnos y Epigramas, intr. vers. rítm. y nts. de Pedro Tapia Zúñiga, México, unAm, Bibliotheca Scriptorum Graecorum et Romanorum Mexicana, 1984.

Denys D' Halicarnasse, La composition stylistique (Opuscules rhétoriques, tome III), Paris, Les Belles Lettres, 2003.

Görgemanns, Herwig, Platon (herausgegeben von G. Alföldy, E. Christmann, A. Dihle, R. Kettemann), Heidelberg, Universitätsverlag C. Winter, 1994.

Homeri Odyssea, recognovit P. von der Muehll, Stutgardiae in aedibus B. G. Teubneri, MCMXCIII, editio stereotypa editionis tertiae (MCMLXII).

LAUSBERG, Heinrich, Elementos de retórica literaria: introducción al estudio de la filología clásica, románica, inglesa y alemana, versión española de Mariano Marín Casero, Madrid, Gredos (Biblioteca Románica Hispánica, III. Manuales, 36), 1975.

Leopold, E. F., Lexicon Graeco-Latinum manuale, Lipsiae (altera editio stereotypa C. Tauchnitiana emendatior et locupletior), sumptibus Ottonis Holtze, 1883.

PAssow, Franz, Handwörterbuch der Griechischen Sprache (unveränderter reprografischer Nachdruck der 5. Auflage, Leipzig 1841), Darmstadt, Wissenschaftliche Buchgesellschaft (WBG), Sonderausgabe 2004.

Platon, Werke, in acht Bänden, Griechisch und Deutsch, herausgegeben von Gunther Eigler, Darmstadt, Wissenschaftliche Buchgesellschaft (WBG), 1977.

Reyes, Bulmaro, "Homero, maestro / estudiante de retórica. ¿Una fantasía Il., IX, vv. 443-444?”, Noua tellus, 14, 1996, pp. 9-34. 